\title{
VOC Sensing Properties of YSZ-Based Gas Sensors Attached with Au-Based Electrodes Prepared by a Drop-Coating Method
}

\author{
Taro Ueda ${ }^{1}$, , Satoshi Ono ${ }^{1}$, Takayuki Suzuki ${ }^{2}$, Kai Kamada1, Takeo Hyodo ${ }^{1}$, Yasuhiro Shimizu ${ }^{1}$ \\ ${ }^{1}$ Graduate School of Engineering, Nagasaki University, Japan, \\ ${ }^{2}$ Gas Equipment R \& D Center, Yazaki Energy System Corporation, Japan \\ *taroueda@nagasaki-u.ac.jp
}

\begin{abstract}
YSZ-based potentiometric gas sensors using a $\mathrm{CeO}_{2}$-added $\mathrm{Au}$ sensing electrode $\left(\mathrm{Au}\left(n \mathrm{CeO}_{2}\right)-\mathrm{dr}, n\right.$ : an additive amount of $\mathrm{CeO}_{2}(\mathrm{wt} \%)$ ) were fabricated by a drop-coating (dr) method, and their sensing properties to toluene and methyl mercaptan were examined in the temperature range of $400-600^{\circ} \mathrm{C}$. The magnitude of response $(\Delta E)$ to $50 \mathrm{ppm}$ toluene increased by the addition of a small amount of $\mathrm{CeO}_{2}$, and the $\mathrm{Au}\left(8 \mathrm{CeO}_{2}\right)$-dr sensor showed the largest response among all the sensors with different amounts of $\mathrm{CeO}_{2}$. The $\mathrm{Au}\left(8 \mathrm{CeO}_{2}\right)$-dr sensor showed an almost linear relationship between the $\Delta E$ and the logarithm of toluene concentration in the range of $20-100 \mathrm{ppm}$ at $500^{\circ} \mathrm{C}$. The balance between the catalytic activity and the electrocatalytic activity for toluene oxidation probably dominates the magnitude of the response. The $\mathrm{Au}\left(8 \mathrm{CeO}_{2}\right)$-dr sensor also showed rather high response to a low concentration of methyl mercaptan $(\Delta E: 17 \mathrm{mV}, 0.1 \mathrm{ppm})$ at $500^{\circ} \mathrm{C}$.
\end{abstract}

Key words: YSZ, solid electrolyte, $\mathrm{Au}, \mathrm{CeO}_{2}$, toluene

\section{Introduction}

Exhaled breath of the patients contains a higher concentration of specific gases than that of healthy people. For example, the patients suffering from lung cancer, diabetes and periodontitis release a high concentration of toluene, acetone and hydrogen sulfide and/or methyl mercaptan, respectively [1, 2]. Among various kinds of gas sensors, solid-electrolyte gas sensors have shown enhanced sensing properties to volatile organic compounds (VOCs) and volatile sulfide compounds (VSCs) by optimizing the sensing electrode (SE) [3]. We have also reported that the addition of $\mathrm{CeO}_{2}$ to the Au SE of yttria-stabilized zirconia (YSZ)based gas sensors increased the toluene response [4], probably due to an increase in the electrochemical activities for toluene oxidation. In this study, we focused on the structural control of the $\mathrm{CeO}_{2}$-added $\mathrm{Au}$ SEs by dropcoating method, in order to increase the sensing properties to toluene and methyl mercaptan.

\section{Experimental}

Typical structure of a sensor fabricated is shown in Fig. 1. Pt current collectors, a Pt counter electrode and a YSZ film were attached to the front side of a porous $\mathrm{Al}_{2} \mathrm{O}_{3}$ substrate, and a Pt heater was attached to the back side of the substrate. In addition, SE was attached on both the YSZ film and the Pt current collector by a drop-coating method. The coating solution was prepared by the addition of $\mathrm{Ce}\left(\mathrm{NO}_{3}\right)_{3} \cdot 6 \mathrm{H}_{2} \mathrm{O}$ and polyvinyl alcohol into a 0.1

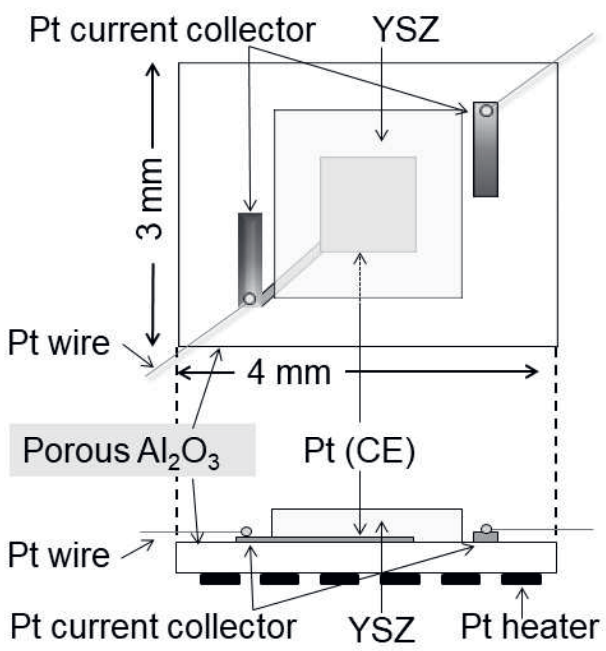

Fig. 1 Schematic view of a YSZ-based gas sensor. 
$\mathrm{M} \mathrm{HAuCl}_{4}$ aqueous solution. A pristine $\mathrm{Au} \mathrm{SE}$ was also prepared by using a $\mathrm{HAuCl}_{4}$ solution only. Then, they were dried at $100^{\circ} \mathrm{C}$ for $10 \mathrm{~min}$ and annealed at $700^{\circ} \mathrm{C}$ for $2 \mathrm{~h}$ in air. The obtained sensors were denoted as $\mathrm{Au}(n \mathrm{MO})-\mathrm{dr}$ ( $n$ : an additive amount of $\left.\mathrm{CeO}_{2}(\mathrm{wt} \%)\right)$. The thickness of the SEs of $\mathrm{Au}\left(n \mathrm{CeO}_{2}\right)-\mathrm{dr}$ sensors was controlled from 2 to $3 \mu \mathrm{m}$ by changing the amount of $\mathrm{Ce}\left(\mathrm{NO}_{3}\right)_{3} \cdot 6 \mathrm{H}_{2} \mathrm{O}$ mixed to the precursor solution. The microstructure of the obtained sensors was examined by SEM, and we confirmed that the structure of SEs was relatively porous. Response properties of the sensors to 20-100 ppm toluene and 0.1-1.0 ppm methyl mercaptan in dry air were measured in a flow apparatus (gas-flow rate: $100 \mathrm{~cm}^{3} \mathrm{~min}^{-1}$ ) in the temperature range of $400-600^{\circ} \mathrm{C}$. The electromotive force $(E, \mathrm{mV})$ of the sensors as a sensing signal was measured with a digital electrometer and the response was defined as the difference in $\Delta E$ between in dry air and in sample gases balanced with dry air.

\section{Results and discussion}

Figure 2 shows response transients to $50 \mathrm{ppm}$ toluene of the sensors fabricated by the dropcoating method at $550^{\circ} \mathrm{C}$ in dry air. The magnitude of response increased with an increase in the additive amount of $\mathrm{CeO}_{2}$, and the $\mathrm{Au}\left(8 \mathrm{CeO}_{2}\right)-\mathrm{dr}$ sensor showed the largest toluene response. However, the further addition of $\mathrm{CeO}_{2}$ decreased the toluene response. Thus, it is confirmed that the existence of an appropriate amount of $\mathrm{CeO}_{2}$ dispersion in the triple phase boundaries of Au/YSZ/gas is effective in improving the toluene response.

Figure 3 shows the temperature dependences of the magnitude of responses of the $\mathrm{Au}\left(n \mathrm{CeO}_{2}\right)$-dr sensors to $50 \mathrm{ppm}$ toluene in dry air. All the sensors showed the largest responses in the temperature range of 500 $600^{\circ} \mathrm{C}$. In addition, the $\mathrm{Au}\left(8 \mathrm{CeO}_{2}\right)-\mathrm{dr}$ sensor showed an almost linear relationship between the $\Delta E$ and the logarithm of toluene concentration in the range of 20-100 ppm (not shown here). The slope, i.e., toluene sensitivity was ca. $42 \mathrm{mV} /$ decade. In our previous study, we have reported that toluene response increased both with a decrease in the catalytic activity for toluene oxidation and an increase in the electrocatalytic activity for electrochemical toluene oxidation of Au SE's [4]. The addition of $\mathrm{CeO}_{2}$ to the $\mathrm{Au}$ SE simultaneously improved these activities, and hence the sensor using a $\mathrm{Au}$ electrode containing an optimal amount of $\mathrm{CeO}_{2}, 8 \mathrm{wt} \%$ in the present study, seems to show the largest magnitude of toluene response. In addition, the difference between temperature dependences of both the activities

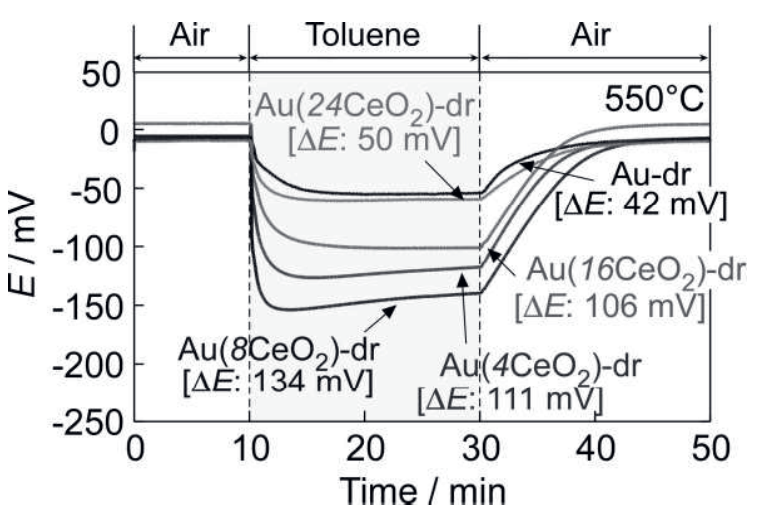

Fig. 2 Response transients to 50 ppm toluene of $\mathrm{Au}\left(n \mathrm{CeO}_{2}\right)$-dr sensors in dry air.

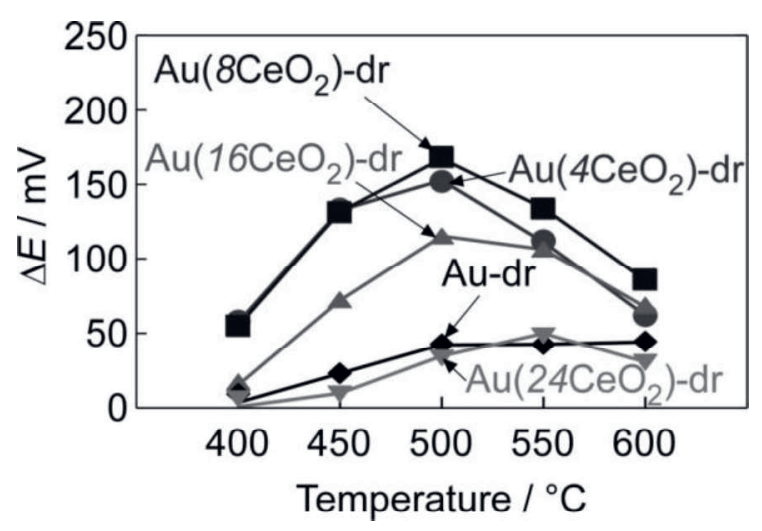

Fig. 3 Temperature dependences of the magnitude of responses of the $\mathrm{Au}\left(n \mathrm{CeO}_{2}\right)-\mathrm{dr}$ sensors to $50 \mathrm{ppm}$ toluene in dry air.

may contribute to the largest toluene response of all the sensors in the temperature range of $500-600^{\circ} \mathrm{C}$

Response properties of the $\mathrm{Au}\left(8 \mathrm{CeO}_{2}\right)-\mathrm{dr}$ sensors to methyl mercaptan were also examined. The sensor showed rather large response $(\Delta E: 17 \mathrm{mV})$ to a low concentration of methyl mercaptan (0.1 ppm) and an almost linear relationship between the $\Delta E$ and the logarithm of methyl mercaptan concentration was obtained in the range of $0.1-0.3 \mathrm{ppm}$. The detail will be discussed in the presentation.

\section{References}

[1] W.-T. Koo, S.-J. Choi, N.-H. Kim, J.-S. Jang, I.-D. Kim, Sens. Actuators B, 223, 301-310 (2016); doi: 10.1016/j.snb.2015.09.095

[2] K. Yaegaki, K. Sanada, J. Periodont. Res., 27, 233-238 (1992); doi: 10.1111/j.1600-0765.1992. tb01673.x/full

[3] N. Miura, T. Sato, S. Anggraini, H. Ikeda, S. Zhuiykov, lonics, 20, 901-925 (2014); doi: 10.1007/s11581-014-1140-1

[4] T. Ueda, H. Abe, K. Kamada, S. R. Bishop, H. L. Tuller, T. Hyodo, Y. Shimizu, Sens. Actuators B, 252, 268-276 (2017); doi: 10.1016/j.snb.2017.05. 172 